\title{
Web-Based Spatial Decision Support: Status and Research Directions
}

\section{Claus Rinner}

University of Toronto

Rinner, C. (2003). Web-based spatial decision support: Status and research directions. Journal of Geographic Information and Decision Analysis, 7(1), 14-31.

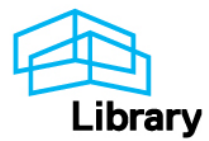




\title{
GIDA
}

Journal of Geographic Information and Decision Analysis

2003, Vol. 7, No. 1, pp. 14-31

\section{Web-based Spatial Decision Support: Status and Research Directions}

\author{
Claus Rinner \\ Department of Geography \\ University of Toronto \\ Toronto, Canada \\ rinner@geog.utoronto.ca
}

\begin{abstract}
This paper summarizes research on Web-based spatial decision support systems (WebSDSS). The review distinguishes early server-side from more recent client-side applications. A third category of WebSDSS focusing on spatial decision support in public participation is typically implemented as a mixed client/server-based system. Conclusions drawn from previous work include the need for systematic user studies of WebSDSS, and the adoption of interoperable architectures for distributed spatial decision support. Furthermore,

a conceptual framework is proposed to facilitate further studies of WebSDSS methods.

KEYWORDS: World-Wide Web (WWW), Internet, Spatial Decision Support Systems (SDSS), Geographic Information Systems (GIS), Public Participation, Decision Services

Acknowledgements I am grateful to the students in my seminar on "Web-based spatial decision support" (summer semester 2003) at the Institute for Geoinformatics, University of Münster, who helped me to review published approaches to WebSDSS. Two anonymous reviewers made helpful suggestions for improving the classification of WebSDSS approaches.
\end{abstract}




\section{Introduction}

Spatial decision support plays an increasing role in geographic information science since the beginning of the 1990s. Although researchers could not agree upon a definition of spatial decision support systems (SDSS) and on how to delimit SDSS from geographic information systems (GIS), SDSS are commonly considered as application-specific software solutions, and GIS are described as generators for SDSS (Keenan 1997).

The core function of an SDSS is to support users in solving complex, semi-structured decision problems (Densham 1991). Decision situations that have a spatial reference usually consist of a large number of decision alternatives with varying properties and, thus, are considered as being complex per se (Malczewski 1999). A decision problem is called semi-structured if it cannot be solved in a deterministic manner, but can be formalized to some extent. Differences in criterion importance weighting between stakeholders is a common factor that prevents a deterministic solution.

The development of SDSS was initiated by advances in non-spatial decision support systems (DSS) in the management sciences in the 1970s. A pivotal component of DSS are functions that support a choice between feasible decision alternatives. Many such components implement algorithms that derive a ranking of alternatives from their attributes. A family of such tools are multi-criteria decision analysis (or multi-criteria evaluation) methods, which include weighted linear combination, analytical hierarchy process, and many more.

Since the emergence of the World-Wide Web in the mid-1990s, both roots of SDSS: DSS and GIS have been related to Internet techniques and used for online applications. On the one hand, Bhargava and Power (2001) provide a status report on Web technologies used for DSS. NWA-Web (2003) and Web-HIPRE (2003) are examples of non-spatial decision analysis tools on the Web. On the other hand, Peng and Tsou (2003) and Green and Bossomaier (2002) provide detailed overviews of Internet GIS techniques. Some of the most popular online geo-spatial applications, such as driving directions (e.g. MapQuest 2003) and property databases (e.g. MLS 2003), combine features of Internet mapping and decision support. Therefore, research into Web-based SDSS (WebSDSS) seems a natural consequence. Rinner and Jankowski (2002) describe technical foundations and applications of WebSDSS. However, there is only a relatively small number of WebSDSS-related publications to be studied, and no systematic overview is known to the author.

Peng and Tsou (2003) describe Internet GIS as client/server systems the basic functions of which - presentation, program logic, and database - are distributed between client and server computers. Depending on the partitioning point, applications range from thin client to thick client approaches on a continuous scale. With regards to the program logic for spatial decision support, we can distinguish between:

- Server-side WebSDSS,

- Mixed client- and server-side WebSDSS, and

- Client-side WebSDSS. 
Server-side WebSDSS appeared in the literature and on the Web since 1996. They perform all decision support-related operations on a server, while the client is only used for the presentation of an HTML-based user interface. HTML forms are used to gather user input, whereas static maps present results of server-side processing. Examples of these classical WebSDSS are described in more detail in section 2 and include Carver et al. (1996), Menegolo and Peckham (1996), Bhargava and Tettelbach (1997), Jensen et al. (1998), and Rinner (2003).

A common motivation for making SDSS accessible online is to support group decisionmaking. Public participation through WebSDSS is promoted by Kingston et al. (2000), Zhu et al. (2001), and Sikder and Gangopadhyay (2002). Discussions are an important part of participatory planning and Voß et al. (2002) propose group decision support for spatial discourses. Online spatial decision support for public participation processes is typically supported by a mix of client- and server-side WebSDSS. Compared to strictly server-side WebSDSS, clients here are typically implemented through Java applets allowing for more interactivity, as described in section 3.

The third category are strictly client-side WebSDSS that represent more recent publications. This research suggests advanced visualization and multi-criteria evaluation methods, and integrates WebSDSS with state-of-the-art in other geographic information techniques. Jankowski et al. (2001) combine cartographic visualization techniques with multi-criteria decision analysis and data mining; Andrienko and Andrienko (2001) propose intelligent user guidance in interactive decision support; and Rinner and Malczewski (2002) introduce decision strategies in WebSDSS (see section 4).

Table 1. Analogy between Web mapping technology categories (Peng and Tsou 2003) and WebSDSS approaches. Data-driven WebSDSS are excluded from this review; public participation GIS feature client- and server-side WebSDSS characteristics; distributed spatial decision support is discussed in the research agenda.

\begin{tabular}{|l|l|}
\hline Web mapping technology & Web-based SDSS \\
\hline Static map publishing & Data-driven WebSDSS \\
\hline Static Web mapping & Server-side WebSDSS \\
\hline Interactive Web mapping & Client-side WebSDSS \\
\hline Distributed GI services & Distributed spatial decision support \\
\hline
\end{tabular}

Peng and Tsou (2003) suggest a classification of Web mapping technology into four classes: (1) static map publishing, (2) static Web mapping, (3) interactive Web mapping, and (4) distributed geographic information services. These categories move along similar lines with earlier classifications 
in Plewe (1997), Fitzke et al. (1997), and Rinner (1998). Based on an analogy between Peng and Tsou's client/server system functions and the components of an SDSS - user interface for presentation and input, model base for program logic, and database for data management - one would expect a total of four WebSDSS categories (see Table 1). However, on the one hand, WebSDSS corresponding to the "lowest" Web mapping category (static map publishing), can be associated with data-driven SDSS focusing on querying and visualizing spatial data. These WebSDSS are not covered in this paper as they lack explicit evaluation methods and are difficult to distinguish from exploratory Web mapping applications. On the other hand, WebSDSS development has not yet reached the level of the "highest" Web mapping category (distributed GI services), but some work towards distributed spatial decision support services is addressed in section 5 .

In addition to the work mentioned so far, several authors utilize keywords related to WebSDSS. However, many papers were found to describe Internet mapping rather than spatial decision support. For example, the "Web-based decision support or advisory tool" proposed by Sugumaran et al. (2000) is limited to visualization and data retrieval to support floodplain management. Bertolotto et al. (2001) describe an Oracle-based technology that includes analysis and reporting functionality but no core decision support methods. Similarly, Takatsuka and Gahegan (2001) emphasize the need for problem insight and "decision sharing" but do not offer explicit decision support techniques in their GeoVISTA Studio applications. These papers demonstrate that the availability of geographic data on the Web may in itself support the decision-making process of individuals and groups.

Important issues identified from the literature review include the need for empirical user studies; the theoretical foundation of WebSDSS and its relation to classical SDSS frameworks; and the conformance of WebSDSS with up-to-date distributed geo-processing architectures. Section 5 summarizes the current status of research in Web-based spatial decision support and suggests research directions for WebSDSS. The paper concludes with a summary of findings and their implications.

\section{Classical server-side WebSDSS applications}

\subsection{Open spatial decision making on the Internet (OSDM)}

Among the first and most prominent researchers studying Web-based spatial decision support are Steve Carver and colleagues at the Centre for Computational Geography, University of Leeds. Carver (1991) suggested integrating multi-criteria evaluation (MCE) methods in GIS using the case study of radioactive waste disposal in the UK. In 1996, the group published a similar application on the Web (Carver et al. 1996).

This "open spatial decision making" (OSDM) application is presented as a combined information system and GIS-based spatial decision support system. The client offers (1) a data viewer for pre-defined constraints and factors as well as for the result of user-guided evaluation, (2) an uncommon a-priori location decision by the user, (3) data selection and weighting menus, and (4) a 
feedback form. The resulting suitability map is derived from a multi-criteria evaluation algorithm on the server.

The system's client-server architecture is developed from scratch using HTML forms to present the client component in any standard Web browser, and the $\mathrm{C}$ programming language for the GIS engine and MCE tool on the server. The "iterative, semi-structured decision path" of the OSDM application offers users some options to explore the radioactive waste disposal problem before coming to a location choice.

The motivation for making this application available online was drawn from the wider public access to data and tools for spatial planning and decision-making. Table 2 visualizes the aim of moving up the "public participation ladder" (Carver et al. 1998) to achieve virtual democracy. Most planning regulations still limit public involvement to the right to object.

Table 2. Moving up the "public participation ladder" (after Carver et al. 1998). Highest level attained in many societies is the public's right to object to planning projects.

\begin{tabular}{|c|c|}
\hline \multirow{6}{*}{ 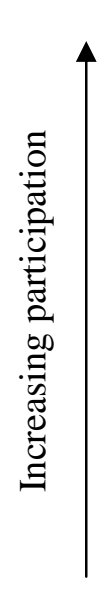 } & Public participation in final decision \\
\hline & Public participation in assessing risks and recommending solutions \\
\hline & Public participation in defining interests, actors, and determining agenda \\
\hline & Public right to object \\
\hline & Informing the public \\
\hline & Public right to know \\
\hline
\end{tabular}

Carver and colleagues further developed this participatory approach in a different case study, which is described in the public participation WebSDSS section below. There is an empirical user study integrated in OSDM by means of the feedback form, which includes information about the location decision by the user, but no results are reported. A major motivation for the researchers to publish OSDM was to experiment with Web design for participatory SDSS at an early stage of Web development.

\subsection{Multi-criteria geographic information system (MC-GIS)}

Menegolo and Peckham (1996) introduce MC-GIS, a "fully integrated tool for site planning using multi criteria evaluation techniques within a GIS". The paper does not describe a Web-based system, but we know from Malczewski (1999) that MC-GIS was available on the Internet until about 1999. 
MC-GIS supports decision-makers in a preliminary screening step as well as in a final evaluation and site selection step. Screening is based on spatial analysis functions in the GIS component of the system. It lets the user process raster layers with relevant criteria to determine those areas that satisfy thresholds on the criteria (constraints).

A link between the GIS component and a decision matrix allows users to specify up to five candidate locations within the suitable areas for further analysis. The data for these locations is loaded in the matrix that is the basis for final evaluation. Criterion outcomes are aggregated using either reference point method or concordance/discordance analysis (ELECTRE II).

Menegolo and Peckham (1996) describe a case study for a site selection problem in the Lombardy region. Malczewski (1999) studies the Internet version of the same case study. According to him, Intergraph's MGE was used as the server-side GIS, while the client consists of HTML forms to be displayed and filled in a Web browser.

\subsection{Recycling decision support system}

Bhargava and Tettelbach (1997) present a Web-based system that supports consumers in finding the best options to dispose of recyclable materials. This system provides a route finding algorithm with time and cost/benefit constraints, so that users can find a sequence of recycling stations to visit in limited time and with minimum recycling cost (or maximum benefit in case of payoff for certain waste items).

The Web installation of this system does not only increase consumers' accessibility to information and analytical tools, but also allows recycling stations to maintain accurate information

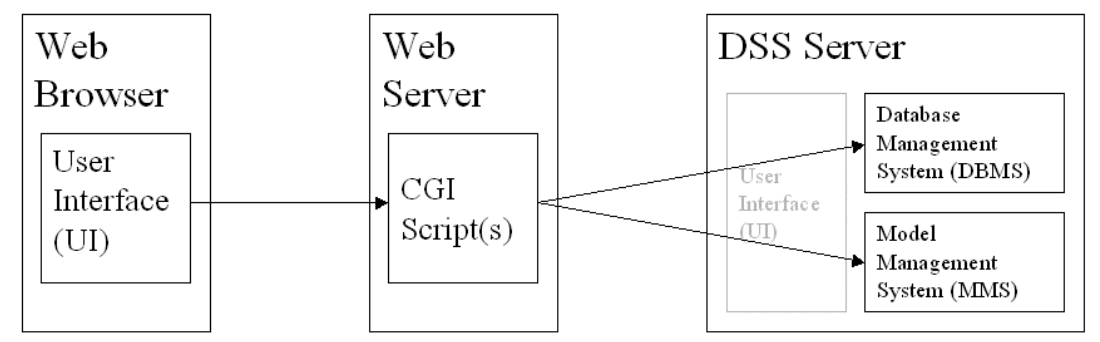

Figure 1. Architecture of a Web-based DSS

(after Bhargava and Tettelbach 1997) such as address, phone numbers, and fees/payoff remotely.

The authors describe the architecture of the recycling DSS with reference to standard (nonspatial) DSS architecture consisting of database management system

(DBMS), model management system (MMS), and user interface (UI). In Web deployment, the UI component is moved to the client and presented as HTML forms in a Web browser. DBMS and MMS remain on a DSS server and are addressed by the client using CGI scripts. This model architecture is shown in Figure 1. 
The DBMS component handles two types of data, general data about recycling stations, and user-specified data about a planned recycling activity. The second type of data is gathered from the client and fed into a utility optimization model implemented in the AMPL environment. The results of server-side computation are displayed on the client in the form of a HTML text page. Although distance constraints are the only reference to the spatial nature of the recycling problem, and no travel map or other cartographic visualization is included, the prototype can still be considered an excellent example of WebSDSS technique.

The Recycling DSS has been developed with support from the Monterey regional waste management district, but no realistic user study is reported in the paper. Unfortunately, the prototype is not available on the Internet any more.

\subsection{Decision support in crop management (PI@nteInfo)}

Pl@nteInfo is a Web platform that supports farmers' decisions in crop management (Jensen et al. 1998). The system combines static documents with databases and simulation models. Users can access static information about crop diseases and results of dynamic simulation of disease risk on the base of real-time data on weather and current pest recording.

Pl@nteInfo uses two central Web servers for information, data, and models. The user interface consists of HTML pages in a client's Web browser. Results of data queries and simulation runs are assembled using Perl CGI scripts. Graphs for risk calculations are generated using SAS programs. There is no cartographic output and spatial references are not explicit in the system. This system has been put online in 1997 and is still operating on a subscription basis.

\subsection{Internet mapping for online decision support}

Rinner (2003) demonstrates the use of Internet map server technique for online decision analysis. The paper extends classical approaches in that it provides access to dedicated decision support functions of a server-side GIS in contrast to mapping and spatial analysis functions. In this case, Web access to SDSS is motivated by the use in teaching.

The online application is based on the Idrisi desktop GIS and provides access to parts of Idrisi's decision support tutorial. More specifically, users can view input data sets with potential decision criteria, develop constraint and factor maps, and set preferences for weighted linear combination of factors. The tutorial uses data for a residential development problem in Massachusetts. No user study has been performed so far for this tool. Technically, Idrisi is linked to the Internet through a suite of CGI scripts implemented in Visual Basic. User input is gathered from HTML forms in a standard browser, routed to the scripts, which access decision support modules through Idrisi's API. 


\section{Mixed client/server WebSDSS for public participation}

\subsection{Virtual Slaithwaite}

Virtual Slaithwaite is a model application for public participation in urban planning. Kingston et al. (2000) aim at increasing and improving citizen's involvement in planning processes by providing an online town map with the possibility of attaching notes to point locations in the planning area. These annotations are represented by points on the map so that subsequent users can view existing comments. Thus, decision support offered by this application consists of methods for visualization and communication of opinions on desired urban development.

The dynamic map component of the system is based on the open source Java mapping toolkit GeoTools. The user interface is realized through a Java applet and HTML forms, which are processed by server-side PERL scripts.

Carver et al. (2001) evaluate the use of the Virtual Slaithwaite case study. The data analysis shows a characteristic distribution of age and occupation, although involving school children biased the study. Problems with the handling of the software have been observed but not recorded in a systematic way.

\subsection{Vegetation manager (VegMan and JavaAHP)}

Zhu et al. (2001) describe a Web-based information and decision support system, VegMan, for regional vegetation management. The system was designed to sustain biodiversity and native vegetation in Queensland, Australia. The Internet is used to disseminate information and provide access to analytical tools.

Resources available in VegMan include current information, presented on interactive maps; current policies and regulations presented as text documents; and proposed regional strategies, as texts and on maps. In addition, alternative vegetation management options can be evaluated using a multicriteria analysis tool. The WWW is seen as a means of reaching more stakeholders and the public, and providing better quality information.

VegMan is a client/server system using HTML pages and Java applets as its user interface. On the server side, VegMan consists of three software components, all of which are implemented in Java. A rule-based system developed with JESS answers queries for available vegetation management strategies, assembling HTML documents to return to the user. WebMap is an Internet mapping toolkit used to provide maps along with the text documentation by integrating the WebMap applet into the HTML documents. The third component is JavaAHP, an implementation of the analytical hierarchy process (AHP) multi-criteria evaluation method.

JavaAHP seems only loosely coupled to VegMan as there is no data transfer from the other system components to it. However, JavaAHP by itself can be considered a WebSDSS that uses clientside technique. The applet allows a user to specify a decision problem and handle it according to the 
AHP, including pairwise comparison of decision criteria, calculation of inconsistency ratio, and final assessment of alternative options. A comprehensive report is generated by the system.

\subsection{Collaborative WebSDSS for land-use change assessment}

Sikder and Gangopadhyay (2002) present a synopsis of collaborative spatial decision-making followed by a description of Geo-ELCA, a WebSDSS for exploratory land-use change assessment. This prototype aims at demonstrating how distributed access to geographical information in the context of environmental planning facilitates discourse among stakeholders. The case study presented by the authors is a land-use re-structuration project in a heavily industrialized area in New Jersey.

From the description of the case study, it turns out that Geo-ELCA is mainly used as a tool to test different decision-makers' visions of future land-use against consequences of potential land-use changes (e.g. pollution, flooding). A Web interface allows users to select land parcels and modify land-use. The system then runs simulation models as to predict environmental effects of the modification. However, the architecture of the system is never described, making it difficult to understand how the input of multiple users is stored and combined or discussed.

\subsection{Spatial discourse}

Voß et al. (2002) combine a Web-based groupware, Zeno, with map-centred decision analysis tools in CommonGIS. The paper also introduces an extensive model process for conflict mediation in facility location problems. This approach structures a collaborative decision process into group meetings and phases of individual work on the Web.

In the paper, a preliminary integration of the two systems is applied to the problem of locating bike rental stations in a city. In a role-playing experiment, researchers represented possible stakeholders in order to test the software integration and model process.

The authors demonstrate how a full software integration for spatial discourse would allow users to link discussion contributions to locations on a map, and access discussion from map elements; to explore decision alternatives and their criterion values on interactive maps; to evaluate and rank decision alternatives, and modify this ranking manually; to initiate automatic collection of rankings of multiple users in a voting step; and to explore voting results using the same interactive mapping tools as for exploration of decision space. These innovative elements of comprehensive support of stakeholder discussions and decisions in spatial planning are in the process of implementation.

Voß et al. (2003) describe the architecture of an update of the integrated system in more detail. Zeno is a server-based groupware with a HTML user interface. Discourses in Zeno can be associated with a CommonGIS application that consists of a Java applet with data files loaded to the client. The Zeno UI can feed the applet with information about new discussion contributions to be localized on the associated map. As soon as the user manually provides these geographical references, they are 
stored on the Web server. CommonGIS then is equipped for map-based display of information about contributions and for linking map elements back to Zeno discussions.

\section{Client-side WebSDSS tools}

\subsection{Map-centred exploratory decision analysis}

Jankowski et al. (2001) combine cartographic visualization techniques with multi-criteria decision analysis and data mining. Their prototype software, DECADE, is based on the interactive thematic mapper, Descartes, and the data-mining package, Kepler. The Descartes Java applet has been extended by two multi-criteria evaluation methods: ideal point analysis (IPA), and aspiration levels technique. Dynamically linked displays of decision outcomes and the spatial distribution of alternatives are provided, and users define aspiration levels for IPA on the basis of interactive maps. In addition, users' spatial knowledge can be gathered by the map-based manual classification method.

The mapping component of this WebSDSS prototype is a thick client Java applet that includes multi-criteria evaluation (MCE) methods in the attribute table manipulation tools. IPA results can be visualized like original attribute values, but cannot be stored permanently (due to applet security restrictions). Supposedly, the system is also available as a stand-alone Java application that would allow for persistent storage.

Jankowski et al. (2001) do not specifically motivate the online availability of their system. There is no mention of a user study, but the authors intend to develop their approach towards spatial decision support for distributed groups of stakeholders.

\subsection{Interactive visual tools and intelligent user guidance in spatial MCE}

In addition to the calculation methods described in the previous section, Andrienko and Andrienko (2001) also worked on visual tools to support map-centred decision-making. A prototypical implementation adds "utility bars" and "utility wheels" to the cartographic methods in the Descartes system. These "utility signs" provide visualization for standardized, weighted utility values of selected attributes. The authors also describe an intelligent user guide that helps finding appropriate decision support methods for specified data analysis tasks within the software package.

Descartes (recently re-implemented as CommonGIS) is a complex Java application containing various graphical and cartographic visualization methods, interactive manipulation tools, and basic GIS functions. When installed on the Internet, the software is completely transferred to the client's Web browser as a Java applet, which in turn loads necessary geographic and attribute data files from the Web server. As mentioned before, in this case, saving decision-making results is not possible.

The authors do not emphasize the Internet-compliance of their system and therefore do not provide a motivation for providing it as an online application. It can be assumed that Internetcompliance of this WebSDSS is just an incidental consequence of earlier development of Descartes using the Java programming language. However, this feature could help realize the further research 
envisioned by Andrienko and Andrienko (2001), which is directed towards in-depth user studies of the intelligent guidance system.

\subsection{Decision strategies in WebSDSS}

Rinner and Malczewski (2002) introduce decision strategies in WebSDSS. The authors present a prototype implementation of ordered weighted averaging (OWA) in an Internet-based interactive mapping environment based on the CommonGIS system. OWA is a multi-criteria evaluation method that allows users to define a decision strategy in terms of risk to be taken and tradeoff to be allowed between good and bad criteria, when aggregating criterion values to an evaluation score for each decision alternative.

The motivation for Web-enabling this tool is in providing a large number of users access to a generic decision support method. An important issue was the reduction of complexity of the user interface to the method. However, no user study is presented for the OWA implementation in CommonGIS. This tool is realized as an extension of the CommonGIS Java application/applet in analogy to the ideal point method described in Jankowski et al. (2001) (see section 4.1). In their outlook, Rinner and Malczewski (2002) envision database implementations of MCE methods and Web services-based architectures for spatial decision support.

\section{Research agenda for distributed spatial decision support}

In the literature review we tried to answer the following questions for a representative sample of WebSDSS tools and applications:

1. What definition of "decision support" do the authors adhere to?

2. What was the motivation for providing online access to an application?

3. What technology was used?

4. Did the authors study the use of their system?

5. What is the research area and open issues perceived by the authors?

The review was deliberately limited to systems that provide explicit support for choice between alternatives, and to participatory systems. Thus, the respective authors' understanding of decision support does not vary too much. Where a motivation is given for providing online access, it is in increasing the number of potential users, and the spatial and temporal range of decision support applications. The technology used for WebSDSS relies on Internet mapping techniques, ranging from server-side script processing with thin HTML forms-based clients, to client-side processing with thick Java applets. These different implementation approaches determined the WebSDSS categories suggested above. Almost no user studies are described in the literature casting some doubt on the utility of WebSDSS in general. Also, only one application (PI@nteInfo) seems to have developed into a productive system. Table 3 summarizes the literature review. 
Table 3. Summary of the literature review on Web-based SDSS tools and applications

\begin{tabular}{|c|c|c|c|c|c|}
\hline Authors & $\begin{array}{l}\text { WebSDSS } \\
\text { program logic }\end{array}$ & $\begin{array}{l}\text { Web \& GIS } \\
\text { technology }\end{array}$ & Decision task & $\begin{array}{l}\text { Motivation for } \\
\text { online access }\end{array}$ & User study? \\
\hline $\begin{array}{l}\text { Andrienko \& } \\
\text { Andrienko } \\
(2001) \\
\end{array}$ & Client-side & $\begin{array}{l}\text { Java applet } \\
\text { (Descartes) }\end{array}$ & Site selection & (unknown) & No \\
\hline $\begin{array}{l}\text { Bhargava \& } \\
\text { Tettelbach } \\
\text { (1997) }\end{array}$ & Server-side & $\begin{array}{l}\text { HTML forms, } \\
\text { CGI scripts to } \\
\text { access DBMS } \\
\text { and MMS on } \\
\text { server }\end{array}$ & Routing & $\begin{array}{l}\text { Public access to } \\
\text { application }\end{array}$ & No (unknown) \\
\hline $\begin{array}{l}\text { Carver et al. } \\
(1996)\end{array}$ & Server-side & $\begin{array}{l}\text { HTML forms, } \\
\text { C programs for } \\
\text { GIS and MCE on } \\
\text { server }\end{array}$ & Site selection & $\begin{array}{l}\text { Public access, } \\
\text { experimentation } \\
\text { with Web } \\
\text { techniques }\end{array}$ & $\begin{array}{l}\text { Yes (feedback } \\
\text { form, but no } \\
\text { results } \\
\text { reported) }\end{array}$ \\
\hline $\begin{array}{l}\text { Jankowski et al. } \\
\text { (2001) }\end{array}$ & Client-side & $\begin{array}{l}\text { Java applet } \\
\text { (DECADE) }\end{array}$ & $\begin{array}{l}\text { Allocation of } \\
\text { funds }\end{array}$ & (unknown) & No \\
\hline $\begin{array}{l}\text { Jensen et al. } \\
(1998)\end{array}$ & Server-side & $\begin{array}{l}\text { HTML pages and } \\
\text { forms, Perl CGI } \\
\text { scripts to access } \\
\text { SAS on server }\end{array}$ & $\begin{array}{l}\text { Agricultural } \\
\text { management }\end{array}$ & $\begin{array}{l}\text { Remote access } \\
\text { (restricted) }\end{array}$ & $\begin{array}{l}\text { Yes (ongoing } \\
\text { use but no } \\
\text { results } \\
\text { reported) }\end{array}$ \\
\hline $\begin{array}{l}\text { Kingston et al. } \\
(2000)\end{array}$ & $\begin{array}{l}\text { Client- and } \\
\text { Server-side }\end{array}$ & $\begin{array}{l}\text { HTML forms, } \\
\text { Perl CGI scripts, } \\
\text { Java applet } \\
\text { (based on } \\
\text { GeoTools) }\end{array}$ & Planning & $\begin{array}{l}\text { Collaborative } \\
\text { public access to } \\
\text { application }\end{array}$ & $\begin{array}{l}\text { Yes (Carver et } \\
\text { al. 2001) }\end{array}$ \\
\hline $\begin{array}{l}\text { Menegolo \& } \\
\text { Peckham } \\
(1996)\end{array}$ & Server-side & $\begin{array}{l}\text { HTML forms, } \\
\text { MGE on server }\end{array}$ & $\begin{array}{l}\text { Screening and } \\
\text { site selection }\end{array}$ & (unknown) & No \\
\hline Rinner (2003) & Server-side & $\begin{array}{l}\text { HTML forms, } \\
\text { Visual Basic CGI } \\
\text { scripts to access } \\
\text { Idrisi32 on server }\end{array}$ & $\begin{array}{l}\text { Land-use } \\
\text { allocation }\end{array}$ & $\begin{array}{l}\text { Public access to } \\
\text { method, Distance } \\
\text { learning }\end{array}$ & No \\
\hline $\begin{array}{l}\text { Rinner \& } \\
\text { Malczewski } \\
(2002) \\
\end{array}$ & Client-side & $\begin{array}{l}\text { Java applet } \\
\text { (CommonGIS } \\
\text { with extension) } \\
\end{array}$ & Site selection & $\begin{array}{l}\text { Public access to } \\
\text { method }\end{array}$ & No \\
\hline $\begin{array}{l}\text { Sikder \& } \\
\text { Gangopadhyay } \\
(2002)\end{array}$ & $\begin{array}{l}\text { Client- and } \\
\text { Server-side? }\end{array}$ & (unknown) & Planning & $\begin{array}{l}\text { Public access to } \\
\text { application }\end{array}$ & No (unknown) \\
\hline $\begin{array}{l}\text { Voß et al. } \\
(2002)\end{array}$ & $\begin{array}{l}\text { Client- and } \\
\text { Server-side }\end{array}$ & $\begin{array}{l}\text { Java applets/ } \\
\text { servlets } \\
\text { (CommonGIS, } \\
\text { Zeno) } \\
\end{array}$ & Planning & $\begin{array}{l}\text { Collaborative } \\
\text { public access to } \\
\text { method }\end{array}$ & $\begin{array}{l}\text { Yes (role- } \\
\text { playing } \\
\text { experiment) }\end{array}$ \\
\hline $\begin{array}{l}\text { Zhu et al. } \\
(2001)\end{array}$ & $\begin{array}{l}\text { Client- and } \\
\text { Server-side }\end{array}$ & $\begin{array}{l}\text { HTML pages, } \\
\text { Java applets/ } \\
\text { servlets (JESS, } \\
\text { WebMap, } \\
\text { JavaAHP) }\end{array}$ & $\begin{array}{l}\text { Vegetation } \\
\text { management }\end{array}$ & $\begin{array}{l}\text { Public access to } \\
\text { application and } \\
\text { method }\end{array}$ & No (unknown) \\
\hline
\end{tabular}

In the cited papers, no future research direction is mentioned predominantly. Most authors limit their outlook to claiming in-depth user studies for WebSDSS and public GIS. The following section describes a potential approach to performing such user studies. It has turned out difficult to compare WebSDSS due to a lack of commonly accepted reference terms. Therefore, we suggest a 
conceptual framework for the development of WebSDSS, which might be helpful for further classifying and adapting these tools to specific application requirements (section 5.2). On this basis, section 5.3 puts WebSDSS techniques in relation to the current trend in GIS towards service-based architectures, advocating for Web-based decision services as the building blocks for future WebSDSS.

\subsection{Practical applications and user studies}

Web-based spatial decision support technologies still wait to be subject to thorough empirical analysis. Real-world WebSDSS applications would be the best environment to perform structured user studies; role-playing experiments may be a viable alternative. Under whatever scenario, a sound framework for controlling the study is required in order to draw valid results from observations. This has not always been the case in GIS-related research.

On this background, Jankowski and Nyerges (2001) propose the Enhanced Adaptive Structuration Theory, version 2 (EAST2), as a theoretical framework for research into participatory GIS. EAST2 is demonstrated to help structure and analyze group decision support situations. Among the constructs controlled by the framework are social interaction, influence of tools, and decision outcomes.

Systematic study of the use of specific WebSDSS applications should be guided by a rigorous framework such as EAST2. However, the particular context of using WebSDSS may challenge the generality of existing frameworks. For example, users may be impossible to control when they are distributed in space and in time. It is an open research question in itself to develop theoretical frameworks for systematic studies of Web-enabled geo-processing applications.

\subsection{WebSDSS generators and toolboxes}

Densham (1991) reviews the three-level framework for building DSS by Sprague (1980), and transfers it to the development of SDSS. According to this model, SDSS are specific applications, which are built from an SDSS generator. SDSS generators in turn consist of SDSS tools. The tools include in particular programming languages, code libraries, and application programming interfaces (APIs) (Malczewski 1997). Keenan (1997) argues for viewing GIS (plus a model component) as the natural SDSS generators.

The online Idrisi tutorial (Rinner 2003) described in section 2.5 can be used as a model for transferring the SDSS development framework to WebSDSS. A number of Idrisi decision support modules such as MCE, FUZZY, and JPGIDRIS are accessible via Idrisi's Visual Basic API. In addition to Web server components such as the HTTP protocol handling and the CGI capacity, these WebSDSS tools are put together to form Idrisi online. Idrisi online was used as a WebSDSS generator when building the online decision support tutorial. From the same generator, different applications could be built. Instead of the cited decision support modules, other modules such as MOLA could be put together to build a different, Idrisi-based generator for multi-objective land allocation support. 
This again could be used as a generator to produce different specific WebSDSSs. This is to argue that WebSDSS development can be conceptualized using the classical three-level approach if we add Web technology to the tool level (see Figure 2).

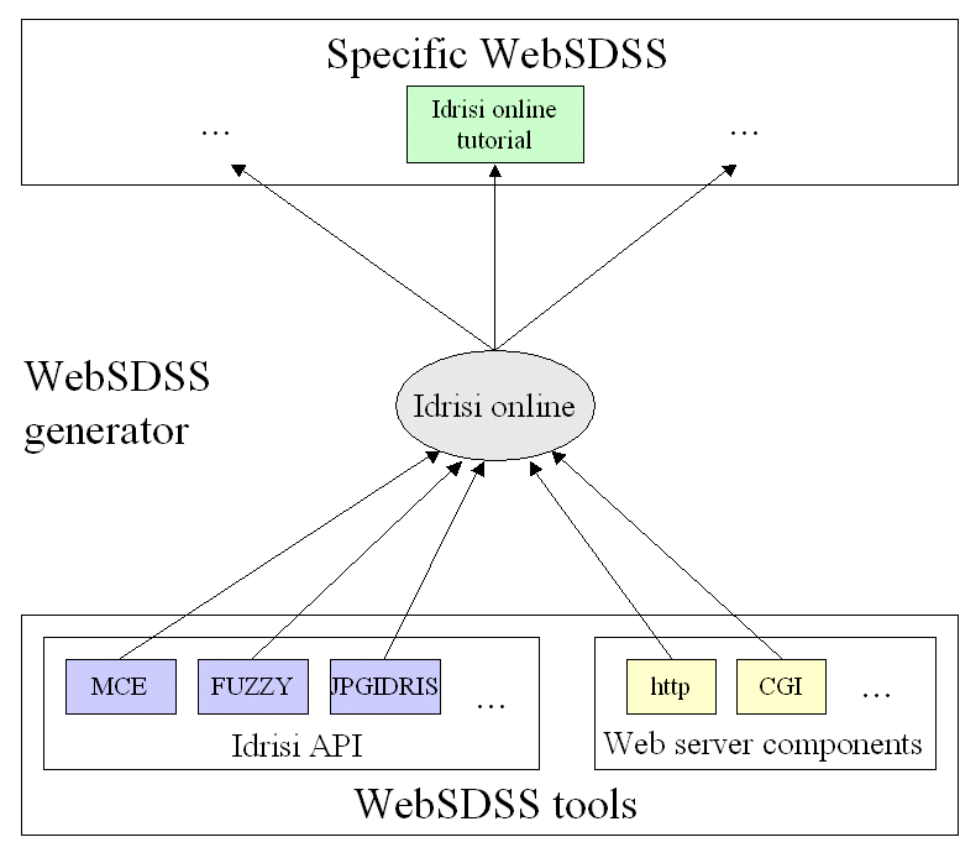

Figure 2. Extension of Sprague's three-level framework (after Densham 1991) to WebSDSS development - the example of the Idrisi online tutorial in Rinner (2003).

\subsection{Spatial decision support services}

With reference to earlier papers, Bhargava and Power (2001) review possible benefits of Web technology to the development of decision support systems (DSS). One of the opportunities identified is "offering decision computation technologies as services on the Web", and using the "Web as computer". The authors provide evidence of two DSS companies that already provide decision services on the Web.

Feeney et al. (2001) establish a link between decision support for sustainable development and spatial data infrastructures (SDI). Their argument is mainly based on the requirement for crossdisciplinary data access, but the authors also request online access to multi-criteria decision models.

Bernard et al. (2003) suggest to provide Web-based multi-criteria evaluation based on spatial data infrastructures. According to ISO and OpenGIS specifications, SDIs provide access to geo-processing methods rather than to data alone. (Data access is seen as a type of method by itself.) More interestingly, advanced method deployment in SDIs is just starting. The authors propose components for a regional assessment and decision support system based on existing OpenGIS specifications. In particular, they suggest using a Web Map Server for overlay of weighted criterion maps in order to produce a subjective assessment map for regional climate change vulnerability. 
Complex geo-processing services such as spatial decision support services (SDSServices) are realized through chaining of basic services (ISO 2002). It may be helpful to conceptualize SDSService development with reference to SDSS development as described above. Figure 3 shows the analogy between SDSS tools and basic geo-processing services, and between SDSS generators and service chains, on the way to compose specific SDSS or specific SDSServices, respectively.
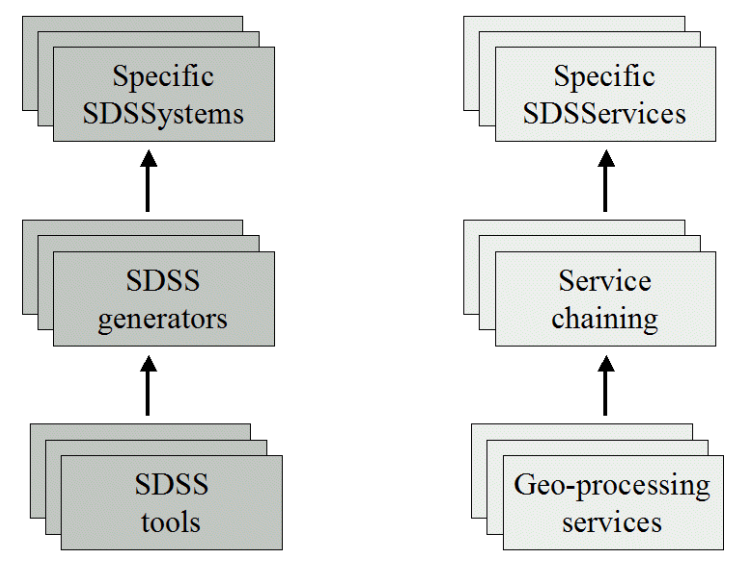

Figure 3. Analogy between SDSS development framework (Densham 1991) and the development of spatial decision support services in spatial data infrastructures

A hot research topic related to SDIs is semantic interoperability. Web service interfaces are specified primarily with respect to syntactic interoperability. This leads to problems when services are provided for users in a specific application domain: Users coming from different contexts may be able to access these services without being aware of differences in the meaning of data or methods. This can be expected to have an impact on the composition of SDSServices as well. For an account analysis of semantic interoperability issues in GIS, see Bishr (1998).

Another important trend in geographic information research and development are locationbased services (LBS). LBS provide users of mobile devices with access to GIS applications, which employ the user's current location to answer queries such as finding the closest facility of a certain type, e.g. an Italian restaurant. Current LBS are limited to non-compensatory filtering and selection operations, but we anticipate SDSServices development to help add user-guided decision analysis methods to LBS in the near future. Users would then be supported in trading off good against poor characteristics of alternative destinations in a multi-criteria evaluation.

\section{Conclusions}

This paper provides an overview of the state of the art in Web-based spatial decision support, and highlights possible directions for further research. The scope of the review sections has been limited to systems that provide core decision support functionality, i.e. support for choice or consensus finding. 
Selected representative WebSDSS applications have been found to fall into one of three categories: server-side, client-side, or mixed applications.

The review was then used to discover trends in research and technology, and the need for a structural framework for WebSDSS. The framework suggested here refers to the classical three-level framework for SDSS development. The most important single issue in current WebSDSS research seems to be a need for systematic user studies. At the same time, important technological shifts can be expected for WebSDSS due to the advent of spatial data infrastructures based on Web services. In the future, we are likely to see interoperable geo-processing services that can be chained to build specific spatial decision support services. Related research is required in the areas of semantic interoperability and mobile GIS.

\section{References}

Andrienko, N.V., and Andrienko, G.L. (2001) Intelligent Support for Geographic Data Analysis and Decision Making in the Web, Journal of Geographic Information and Decision Analysis, 5(2), 115-128.

Bernard, L., Ostländer, N., and Rinner, C. (2003) Impact Assessment for the Barents Sea Region - A Geodata Infrastructure Approach. Proceedings of AGILE - 6th Conference on Geographic Information Science held in Lyon, France, on April 24-26 2003, pp. 653-661.

Bertolotto, M., Carswell, J.D., McGeown, L., and McMahon, J. (2001) e-Spatial Technology for Spatial Analysis and Decision Making in Web-based Land Information Management Systems, Journal of Geographic Information and Decision Analysis, 5(2), 95-114.

Bhargava, H.K., and Tettelbach, C.G. (1997) A Web-based DSS for Waste Disposal and Recycling, Computers, Environment and Urban Systems, 21(1), 47-65.

Bhargava, H.K., and Power, D.J. (2001) Decision Support Systems and Web Technologies: A Status Report. Proceedings of Americas Conference on Information Systems held in Boston, MA, on August 3-5 2001.

Bishr, Y.A. (1998) Overcoming the semantic and other barriers to GIS interoperability, International Journal of Geographical Information Science, 12(4), 299-314.

Carver, S. (1991) Integrating multicriteria evaluation with GIS, International Journal of Geographical Information Systems, 5(3), 321-339.

Carver, S., Evans, A., Kingston, R., and Turton, I. (1998) Geographical Information Systems on the World Wide Web: improving public participation in environmental decision making. Proceedings of Conference of the European Association for the Study of Science and Technology held in Lisbon, Portugal, on September 30 - October 31998.

Carver, S., Evans, A., Kingston, R., and Turton, I. (2001) Public participation, GIS and cyberdemocracy: evaluating on-line spatial decision support systems, Environment and Planning B: Planning and Design, 28(6), 907-921. 
Carver, S.J., Blake, M., and Turton, I. (1996) Open Spatial Decision Making: Where to Dispose of Britain's Radioactive Waste? URL: http://www.ccg.leeds.ac.uk/mce.

Densham, P.J. (1991) Spatial decision support systems. In: D.J. Maguire, M.F. Goodchild, D.W. Rhind (eds.) Geographical information systems: principles and applications, pp. 403-412. London: Longman.

Feeney, M.-E., Rajabifard, A., and Williamson, I.P. (2001) Spatial Data Infrastructure Frameworks to Support Decision-Making for Sustainable Development. Proceedings of the 5th Global Spatial Data Infrastructure (GSDI) Conference held in Cartagena, Colombia, on May 22-24 2001.

Fitzke, J., Rinner, C., and Schmidt, D. (1997) GIS-Anwendungen im Internet [GIS Applications in the Internet]. Geo-Informations-Systeme, 6, 25-31.

Green, D., and Bossomaier, T. (2002) Online GIS and Spatial Metadata. London: Taylor \& Francis.

ISO (2002) Geographic Information Services Draft ISO/DIS 19119.

Jankowski, P., and Nyerges, T.L. (2001) Geographic Information Systems for Group Decision Making. London: Taylor \& Francis.

Jankowski, P., Andrienko, G.L., and Andrienko, N.V. (2001) Map-Centered Exploratory Approach to Multiple Criteria Spatial Decision Making, International Journal of Geographical Information Science, 15(2), 101-127.

Jensen, A.L., Thysen, I., Boll, P.S., and Pathak, B.K. (1998) Pl@nteInfo: A World Wide Web based Decision Support System for Crop Production Management in Denmark. Proceeding of the first Asian conference for Information Technology in Agriculture held in Wakayama-City, Japan, on January 24-26 1998, pp 125-129.

Keenan, P. (1997) Using a GIS as a DSS Generator, University College Dublin, URL: http://mis.ucd.ie/staff/pkeenan/gis_as_a_dss.html.

Kingston, R., Carver, S., Evans, A., and Turton, I. (2000) Web-based public participation geographical information systems: an aid to local environmental decision-making, Computers, Environment and Urban Systems, 24, 109-125.

Malczewski, J. (1997) Spatial Decision Support Systems, NCGIA Core Curriculum in GIScience, URL: http://www.ncgia.ucsb.edu/giscc/units/u127/u127.html

Malczewski, J. (1999) GIS and Multicriteria Decision Analysis. New York: John Wiley \& Sons.

MapQuest (2003) Maps and driving directions, URL: http://www.mapquest.com.

Menegolo, L., and Peckham, R.J. (1996) A fully integrated tool for site planning using multi criteria evaluation techniques within a GIS. In: M. Rumor, R. McMillan, and H.F.L. Ottens (eds,) Geographical Information, pp. 621-630. Amsterdam: IOSA Press.

MLS (2003) Multiple Listing Service, URL: http://www.mls.ca

NWA-Web (2003) Nutzwertanalyse im Internet (Demo), URL: http://www.ifip.tuwien.ac.at/lehre/demo/krames/index.html 
Peng, Z.-R., and Tsou, M.-H. (2003) Internet GIS: Distributed Geographic Information Services for the Internet and Wireless Networks. Hoboken: John Wiley \& Sons.

Plewe, B. (1997) GIS Online: Information Retrieval, Mapping, and the Internet. Santa Fe, NM: OnWord Press.

Rinner, C. (2003) Teaching Spatial Decision Analysis with Idrisi Online. Proceedings of AGILE - 6th Conference on Geographic Information Science held in Lyon, France, on April 24-26 2003, pp. 703-709.

Rinner, C. (1998) Online Maps in GeoMed - Internet Mapping, online GIS and their application in Collaborative Spatial Decision-Making. Proceedings of International Conference on Geographic Information (GIS PlaNET'98) held in Lisbon, Portugal, on September 7-11 1998.

Rinner, C., and Malczewski, J. (2002) Web-Enabled Spatial Decision Analysis Using Ordered Weighted Averaging (OWA), Journal of Geographical Systems, 4(4), 385-403.

Rinner, C., and Jankowski, P. (2002) Web-based Spatial Decision Support - Technical Foundations and Applications. In: The Encyclopedia of Life Support Systems (EOLSS), Theme 1.9 Advanced Geographic Information Systems (edited by Claudia Bauzer Medeiros). Oxford, UK: UNESCO / Eolss Publishers.

Sikder, I.U., and Gangopadhyay, A. (2002) Design and Implementation of a Web-Based Collaborative Spatial Decision Support System: Organizational and Managerial Implications, Information Resources Management Journal, 15(4), 33-47.

Sprague, R.H. (1980) A framework for the development of decision support systems, Management Information Sciences Quarterly, 4, 1-26.

Sugumaran, R., Davis, C.H., Meyer, J., Prato, T., and Fulcher, C. (2000) Web-Based Decision Support Tool for Floodplain Management using High Resolution DEM, Journal of Photogrammetric Engineering and Remote Sensing, 66(10), 1261-1265.

Takatsuka, M., and Gahegan, M. (2001) Sharing Exploratory Geospatial Analysis and Decision Making using GeoVISTA Studio: From a Desktop to the Web, Journal of Geographic Information and Decision Analysis, 5(2), 129-139.

Voß, A., Voß, H., Gatalsky, P., and Oppor, L. (2002) Group Decision Support for Spatial Planning. Proceedings of Urban Data Management Symposium held in Prague, Czech Republic, on October 01-04 2002.

Voß, A., Voß, H., Gatalsky, P., and Oppor, L. (2003) Prototype and Further Requirements of a Real Participatory GIS. Proceedings of AGILE - 6th Conference on Geographic Information Science held in Lyon, France, on April 24-26 2003, pp. 613-622.

Web-HIPRE (2003) Web-HIPRE: Global Decision Support, URL: http://www.hipre.hut.fi/.

Zhu, X., McCosker, J., Dale, A.P., and Bischof, R.J. (2001) Web-based decision support for regional vegetation management, Computers, Environment and Urban Systems, 25(6), 605-627. 